Ideally, there should be a single general scheme for the speedy examination of foodstuffs when their history of treatment is unknown. But the committee also says that there is a need for more basic research on the metabolism of many pesticides-carbamates, dithiocarbamates and organophosphorus insecticides, for example.

Imported foodstuffs present a particularly difficult problem. Concentrations of pesticides used in good agricultural practice, which the working group defines as that which achieves the desired technological advantage with the minimum of residue, may vary with climatic conditions. A further difficulty is that trade agreements usually stipulate that there must be no discrimination between imported and home produce on technical grounds, and the report declares that it would be unfair to have a double standard for levels of pesticide contamination in home and foreign produce. Some compromise will have to be worked out and a system devised for sampling imported produce at its port of entry.

There remains the problem of collecting data, published and unpublished. The working party says that the Government should urgently collect it together, persuading industry to release new information. Given the cooperation of industry, the working group considers there is no need to increase the number of government chemists working on pesticides, but the report recommends the establishment of a small group to collect samples for analysis and a new committee to replace the Panel on Pesticides in Foodstuffs. The new committee, to which the Medical and Agricultural Research Councils and the Association of Public Analysts should be asked to contribute members, would initiate research, collate and publicize results and make recommendations for limits of contamination.

\section{NATIONAL TRUST}

\section{lingle of Coin}

Increased public access to National Trust houses and gardens, the replacement of Enterprise Neptune-the campaign to save the coastline of England, Wales and Northern Ireland-by a general appeal for $£ 5$ million, and a drive for increased membership are some of the recommendations of a committee under the chairmanship of Sir Henry Benson in a report to the council of

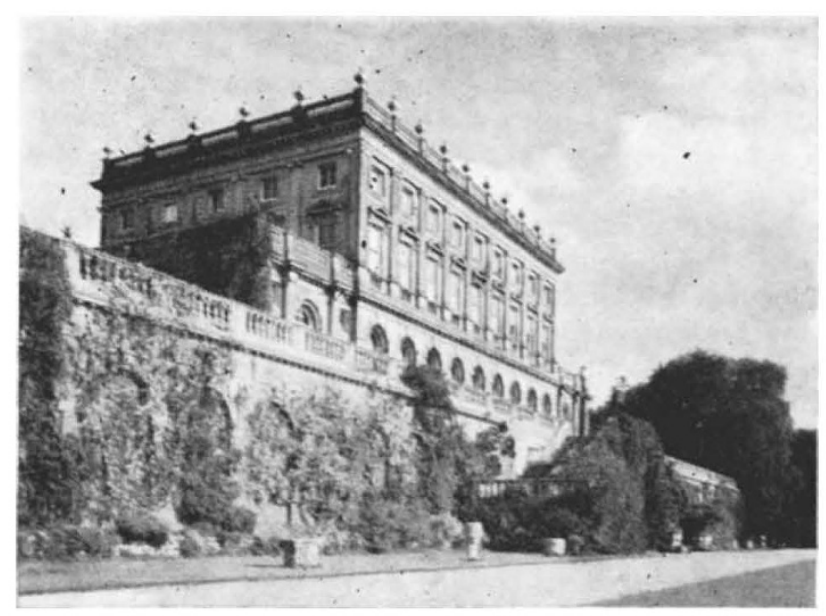

National Trust property-Cliveden, in Buckinghamshire. the trust (The National Trust, 20s). The committee reaffirms that the trust's first responsibility is the preservation by acquisition of places of historical interest or natural beauty, although it does foolishly repeat a statement by the chairman that the trust is "not part of the tourist industry". It does, however, make very clear that the public should be allowed much more access than at present to trust properties in spite of the way in which properties can become too popular __"some properties are already over-visited and in such cases as these we consider that the trust should not be afraid of imposing restrictions". The general rule, however, should be access on both Saturdays and Sundays, and morning as well as afternoon opening should be provided. The minimum period of opening should be from Easter weekend to September 30 .

Although much of the Benson report is taken up with discussion of the internal organization of the trust -it calls for changes in the trust's organization and administration, disturbed in the internal bickerings of two years ago-its principal emphasis is on the trust's present and future finances. Although there is no case for running the trust on strictly commercial lines, the committee leaves no doubt that the dedicated amateur approach of the early days must now be changed. Money must nevertheless be found, and the committee asks that the sum of $£ 4.75$ million to restore and main. tain National Trust properties should be raised by an appeal for $£ 5$ million. In addition, more money is needed to pay for the increasing costs of administration. The committee therefore proposes that the trust should. aim for an increase in members from the present 108,000 to 500,000 in 15 years time, and, on the basis of a $£ 2$ subscription rate for new members, it sets a short-term target of an income from annual subscriptions of not less than $£ 400,000$ by the end of 1970 . Other suggestions for additional income include the continuation and expansion of the trust's policy for letting holiday cottages, and more tours of trust properties. It would also help, the committee says, if the trust was more selective when selecting further properties.

The trust likes its properties to be occupied--it has believed all along that a house should be preserved as a living entity. Often the occupier is the donor or his family or his successors, but some of the properties are let to other tenants, educational institutions included. Visitors to Cliveden House, given to the trust in 1942, have not been greeted by Lord Astor for a few years now. Soon they will be greeted by American students from Stanford University. In January this year, the university took over a 21 -year lease on the house to provide a base for students in Europe on a six-month liberal arts course.

\section{SURVEYING Slow Change to Metric}

The Ordnance Survey, responsible for surveying the whole of Britain on scales ranging from $\frac{1}{4}$ of an inch to 25 inches per mile, seems to be facing with some equanimity the colossal task of converting all its maps to decimal scales and metric units. Until 1980 the staff of the Ordnance Survey will devote most of its time and energy to completing and bringing up to date the National Survey, but the hope is that, after that, it will be able to concentrate on the conversion. In the 
annual report for 1968 (HMSO, 15s), the plans for metrication are outlined. The more detailed maps are already on decimal scales, $1: 1,250$ and $1: 2,500$, and the survey has decided to adopt the $1: 10,000$ scale in place of the 6 inch. For all these maps, contours will have to be replotted at metric intervals and new spot heights measured. In view of the attachment of farmers to the acre, areas of parcels of land will be marked in both hectares and acres. Converting the smaller-scale maps will be the next step.

This year, more maps than ever before have been surveyed in the field and published, despite the high staff turnover rate. By 1969, surveys of the principal urban areas of Scotland, England and Wales at a scale of $1: 2,500$ will be completed. On the research side, the potentialities of the new hydrostatic levelling technique which involves observing simultaneously the water levels in glass gauges at the ends of a long water filled tube are being tested. This technique should be much more accurate than conventional spirit levelling techniques. The Ordnance Survey spent about $£ 7$ million last year and made about $£ 2$ million from selling maps, copyright fees and by charging government departments for the special mapping and other services provided for them by the Survey.

Other British surveyors working for the Ministry of Overseas Development are braving volcanoes, sleeping sickness and being mistaken for headhunters to map areas intended for now settlements, agricultural improvement and engineering works. In its annual report (HMSO, $13 s 6 d$ ), the Direetorate of Overseas Surveys summarizes the assistance it has given to fifty developing countries. Particularly interesting projects in Africa include mapping the area around Lake Victoria, which the Tanzanians hope to use for an irrigation project, and surveying Botswana. In the Pacific, a new survey of the Gilbert and Ellice Islands has been made to provide the basis of a property registration system. The directorate has for a long time been issuing maps on decimal scales, and will in future use metric units on maps for countries that use the metric system. The countries themselves will probably undertake the conversion of old maps.

\section{NUTRITION}

\section{Disease and Dief}

IT is perhaps common knowledge that a malnourished, person is unusually susceptible to disease, and that infectious diseases can influence the nutritional status. Kwashiorkor, for example, is a disease of protein deficient children which is precipitated by infection. The details of the complex interactions between nutrition and infection arc less well known, however. In man, the interactions are regularly synergistic-malnutrition and infection are mutually aggravating and produce more serious consequences than would be expected from a summation of the independent effects of the two. In some laboratory animals, however, a reverse antagonistic effect is observed when highly specific deficiencies inhibit the multiplication of the infectious agent more than they influence the resistance of the host (WHO Report on Interactions of Nutrition and Infection, $£ 214 s$ ).

Bacterial, viral, protozoal and helminthic infections all exert a detectable adverse effect on the nitrogen balance. Keratomalacia (softening and ulceration of the cornea), scurvy and beriberi are frequent aftermaths of an infectious process in people subsisting respectively on diets deficient in vitamin $\mathrm{A}$, ascorbic acid and thiamine, and there is a large body of evidence confirming the adverse effect of infection on the metabolism of these vitamins. Infections also interfere with the metabolism of calcium and phosphorus, and chronic infections alter iron metabolism and erythrocyte production to such an extent that the so-called "anaemia of infection" develops.

Although there is no evidence to suggest that resistance to infections is increased by the addition of ascorbic acid, B-complex vitamins and other specific nutrients to adequate diets, severe deficiencies of these substances do lower the resistance of man to most infectious diseases. Malnutrition directly affects host resistance by interfering with antibody formation, phagocytic activity, endocrine metabolism and nonspecific protective mechanisms. Protein deficiency especially inhibits normal antibody response, and there is evidence that vitamin deficiencies can have the same effects. Vitamin B-complex deficiencies also reduce white blood cell activity, and decreased macrophage activity has been associated with deficiencies of vitamin $A$ and ascorbic acid. Another effect of malnutrition is an alteration in the types, numbers and distributions of intestinal bacteria, and this may bring about a decreased resistance to intestinal infections. Under special conditions, dietary imbalance alters the therapeutic effectiveness of a number of drugs. For example, Plasmodium gallinaceum infection of chicks responded four to twenty times more readily to treatment with sulphadiazine or metachloridine whon the birds were on a purified casein diet rather than on a regular stock diet, but this accentuated therapeutic effect was later eliminated by increased amounts of soy bean in the diet. Antagonistic interactions between a nutritional deficiency and an infection seem to be caused in most cases by a selective lack of one or more nutrients on which the infectious agent is more dependent than the host.

\section{TEACHERS}

\section{Misunderstood Profession}

IT takes a good deal of courage, or perhaps foolhardiness, for the National Union of Teachers to commission a survey into the reasons why teachers are underpaid. For one thing, it implies that the efforts on the teachers' behalf have been unsuccessful, and it also invites people to reply that teachers are underpaid because of the incompetence of the NUT. But if any did say this, their comments were not reproduced in a pamphlet just published by the NUT and entitled "Why Teachers are Underpaid". The pamphlet is the result of a survey carried out for the NUT (by Research Services Ltd) into the attitudes of those who have some influence on teachers' salaries-elected members of education committees, industrialists and businessmen, academics, careers advisers and the like. The interviews revealed, the NUT says, a great deal of ignorance and misunderstanding about the teaching profession.

Indeed, the picture presented by the responses of those interviewed gives a picture of the teaching profession which the NUT can only describe as "a 